\title{
Atenção Básica e Ouvidoria: Um perfil da Interação População e Gestão
}

\author{
Soleane Lavor de Almeida ${ }^{1}$; Shirley Kaliny Correia de Matos ${ }^{2}$; Cleidiane Barbosa Paz $z^{3}$; \\ Onelliany Moreira Leite Lima Santana ${ }^{4}$; Ana Cristina Mortimer Lio de Carvalho ${ }^{5}$; Gislene Farias de Oliveira ${ }^{6}$
}

\begin{abstract}
Resumo: O presente estudo possui como intuito avaliar a interação que existe entre a Ouvidoria e as Unidades da Estratégia Saúde da Família em um determinado município da região sul do estado do Ceará, partindo do pressuposto de que para se oferecer um serviço público de qualidade é essencial escutar a sugestão dos usuários deste, e procurar estar atento aos anseios e expectativas da comunidade. Assim, pois então o estudo se fez onde os dados coletados equivaleram a manifestações da comunidade realizadas na Ouvidoria Municipal de Saúde deste, isto durante todo o ano de 2011. Com esta característica, o estudo foi de natureza quantiqualitativa, exploratória e descritiva, onde dentre os dados coletados na Ouvidoria, procurou-se considerar aqueles relacionados à atenção básica, sendo logo este um critério determinante de exclusão e de inclusão, juntamente com o período, 2011. Com a pesquisa, notificou-se a importância que os serviços desempenhados pela ouvidoria da saúde possuem para avaliar a forma de como os programas de saúde estão sendo desenvolvidos pelos servidores públicos. Em si, pode-se constatar que são, de forma especial, os de nível superior, os que mais são cobrados quanto ao desempenho de atividades em conformidade com as ações apresentadas e divulgadas na implantação dos serviços da atenção básica. Por sua vez, também se constatou o quanto a comunidade cobra a participação de tais profissionais, e de forma indireta expõe essa fiscalização dos serviços. Com o estudo fio possível evidenciar que é na ouvidoria onde se armazena informações importantes que podem ser usadas para a construção de uma política pública de saúde mais democrática e eficiente, sendo que cabe do gestor utilizar essa fonte e meio de exposição da opinião pública sobre os serviços a serem por ele gerenciados, ou então não levar em consideração tais serviços e tomar a ciência de que está agindo sem levar em consideração a opinião do povo.
\end{abstract}

Palavras-Chave: Ouvidoria; Gestão em Saúde da Família; Estratégia Saúde da Família.

\section{Basic Care and Ombudsman: A profile of Interaction Population and Management}

\begin{abstract}
The present study has as objective to evaluate the interaction that exists between the Ombudsman and the units of the Family Health Strategy in a certain town in southerners-State of Ceará, assuming that in order to provide a public service quality is essential to listen to suggestions from users of this, and seek to be attentive to the desires and expectations of the community. Thus, for then the study was done where the data collected amounted to community events held at the Municipal Health Ombudsman this, that throughout the year 2011. With this feature, the study was quant nature, exploratory and descriptive, where the data collected from the Ombudsman; we tried to consider those related to primary care, so this is a criterion of exclusion and inclusion, along with the period, in 2011. Through research, has reported the importance of the services performed by the health ombudsman have to assess the form of how health programs are being developed by public servants. In itself, it can be seen that are so special, the top level, the ones who are cocries about the performance of activities in accordance with the actions presented and disclosed in the implementation of primary care services. In turn, it was also observed how the community charges the participation of such professionals, and indirectly exposes the inspection of services. With the study show that it is possible to wire the ombudsman where he stores important information that can be used for the construction of a public health policy more democratic and efficient, and it is the manager to use this source and means of exposure of the public on the services to be managed by him, or not considering such services and make the science that is acting without taking into account the opinion of the people.
\end{abstract}

Keywords: Ombudsman; Management in Family Health; Family Health Strategy.

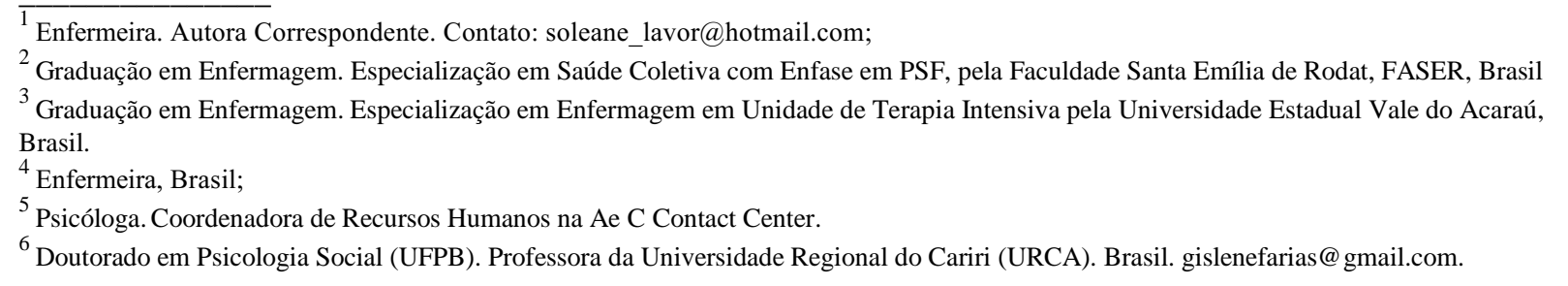




\section{Introdução}

Os serviços de saúde são essenciais para a manutenção positiva da boa qualidade de vida dos membros de uma comunidade. Desde 1988 a República Federativa do Brasil é beneficiada com a implantação de um Sistema Único de Saúde (SUS) que garante serviços básicos de saúde aos seus cidadãos, o qual possui como leis orgânicas a de número 8.080 e 8.142, ambas lançadas em 1990. Este ganhou corpo e tornou-se concreto com a implantação das Equipes de Estratégia Saúde da Família, ocorrido quatro anos depois, sendo um dos grandes benefícios à saúde promovidos nesta época: o Programa Saúde da Família. A Atenção Básica a Saúde, em si, é o nível de gerenciamento dos serviços de saúde onde se encontram profissionais capacitados em desenvolver os processos de prevenção, promoção, reabilitação e tratamento das enfermidades presentes em uma comunidade, logo tal serviço é fundamental para a manutenção, promoção e desenvolvimento da qualidade de vida desta comunidade.

Paralelo à implantação da Estratégia Saúde da Família, já em sua prefiguração, estava na mente dos idealizadores encontrarem algum mecanismo que fizesse com que a população ajudasse a construir e a manter o sistema de saúde. Assim, nos anos 1990 a expectativa de dar condições à comunidade de tal direito tornou-se uma meta das políticas de saúde brasileiras, sendo citada nas reuniões de avaliação deste Sistema Público. Assim foram os encontros ocorridos nesta década, vindo a culminar com as bases legais que floriram em 2003 com a criação do Sistema de Gestão e Estratégia Participativa do SUS (SGEP). Este ato foi crucial na expressão magna da construção conjunta dos serviços de saúde de forma democrática. De tal sistema surgiu o Departamento de Ouvidoria Geral do SUS (DOGES), o qual tem como finalidade ser a ponte entre a população e a gestão do sistema, vindo assim a garantir a qualidade do mesmo e a concretização dos princípios constitucionais deste.

A partir da DOGES a Política Nacional de Gestão Estratégia e Participativa no SUS (Participa-SUS), implantada em 2007, pode ser consumada, a qual é assim caracterizada pelo Sistema Nacional de Ouvidorias do SUS. Paralelo a este processo também se dava forma o serviço de atenção básica que começou com a implantação dos Programas de Agentes Comunitários de Saúde (PACS) em 1987 e culminou em 1994 com a definição do Programa Saúde da Família, onde por meio deste, os serviços de atenção básica a saúde é oferecida a população de forma a vivenciar em sua essência os mesmos princípios constitucionais do SUS.

Diante do pressuposto, fazendo uma relação básica dos temas a serem debatidos no presente estudo: assim como o Programa Saúde da Família é expresso com a implantação das Equipes de Estratégia Saúde da Família onde os programas de saúde são vivenciados no intuito de garantir um estado de bem-estar na comunidade, o Programa do Participa-SUS é vivificado pela atuação das 
Ouvidorias espalhadas por todo o Brasil, onde por meio delas, a comunidade ajuda a dar forma ao Sistema de Saúde no meio social em que se encontra.

Ao analisar a dimensão de tais programas e a amplitude que a concretização destes proporcionou para a boa apresentação da qualidade de vida de uma comunidade, despertou-se o interesse em avaliar quais as argumentações expressas pelos usuários do SUS à ouvidoria de um município, vindo a auxiliá-lo na construção de forma devida de sua estrutura pública de saúde, expressa em sua essência pelos trabalhos desenvolvidos na atenção básica.

A razão disto se dá pelo fato de que se apresenta a Ouvidoria em saúde como a base da criação de modelos administrativos dos programas de saúde. Ou seja, os serviços de saúde são pela ouvidoria: viabilizados, analisados, concretizados e avaliados. De forma geral, é este recurso um magnifico recurso para se vivenciar a gestão participativa.

Diante disso, o presente trabalho tem como objetivo avaliar a interação que existe entre a Ouvidoria e as Unidades da Estratégia Saúde da Família em um município, partindo do pressuposto de que para se oferecer um serviço público de qualidade é essencial escutar a sugestão dos usuários deste, e procurar estar atento aos anseios e expectativas.

\section{Referencial Teórico}

Proporcionar um sistema de saúde que seja publico e democrática é a razão dos trabalhos desempenhados pelos gerentes de saúde em toda nação (ou ao menos deve ser). Em si, desde a década de 1980, que é marcada pela $8^{\circ}$ Conferência Nacional de Saúde, que esta dimensão bilateral da saúde é vista como razão de todo trabalho político a ela desenvolvido. No caso, foram em tal conferência em que foram lançadas as bases constitucionais do Sistema Único de Saúde, expostas no Artigo 196 ao de número 200 da Carta Magna Brasileira, de 1988 e, legalmente viabilizadas pelas leis 8.080 e 8.142 ambas de 1990, sendo a primeira no mês de julho e a segunda em dezembro do citado ano, tornando-se assim, a maior política social em curso na República Federativa Brasileira (BRASIL, 2010a).

Para então desenvolver uma política de saúde eficaz, os gestores federais na década de 1.990 procuraram promover condições para tal curso. Assim, as bases de um Programa Nacional de Participação Social começaram a serem lançadas, vindo a serem culminadas em 2003 na realização da $13^{\circ}$ Conferência Nacional de Saúde. Todavia, até esta data, um processo intensificador de tentativas de implantação de um serviço nacional de ouvidorias havia sido realizado.

Ao apresentar uma linha histórica, Brasil 2010b expõe de forma ampla essa evolução, onde destaco alguns pontos relevantes: a gênese do serviço de ouvidoria se deu em 1996 como uma estratégia de enfrentamento da pandemia da AIDS, onde um número telefônico gratuito foi colocado à disposição da sociedade para dar orientações sobre a doença, por meio do serviço Pergunte AIDS 
(0800-612437), além de outras doenças sexualmente transmissíveis; devido ao amplo número de ligações e de sugestões da população quanto ao desenvolvimento do serviço, em 1997 foi criado o Disque Saúde (0800-611997), onde a população recebia por telefone orientações sobre doenças infecciosas, além das DST's e AIDS, cardíacas, ações políticas de saúde, conselhos de saúde, transplantes de órgãos e tecidos, além de registrar denúncias, reclamações e sugestões ao Ministério de Saúde. De forma genérica o Disque Saúde equivaleu ao princípio básico das atuais Ouvidorias de Saúde.

No caso, a dimensão popular que tal serviço público a saúde ganhou fez com que o Ministério da Saúde ganhasse parcerias importantes para dar forma mais democrática ao SUS, dentre as quais se destaca a feita com o Instituto Nacional do Câncer, onde em maio de 2001 é criado o Disque Pare de Fumar (0800-7037033). No ano seguinte, com as experiências acumuladas por todos os serviços de Discagem Direta, por meio do Decreto $n^{\circ} 4.194$ de 11 de abril de 2002, é criado o Centro Nacional de Promoção da Qualidade e Proteção aos Usuários do SUS, onde todos os serviços de atendimento ao cidadão foram aglutinados.

Diante dos graves crimes contra a mulher e contra a criança e adolescente, ocorridos na época, o Centro Nacional criado em 2002, em 2003 dar forma ao Disque Saúde Mulher (0800-6440803) e Disque Denúncia de Abuso e Exploração Sexual Contra Crianças e Adolescentes (0800-990500). Diante do fato, com a grande repercussão que ganhou os sistemas criados, o Presidente da República da época, Luís Inácio da Silva, lança mais um Decreto Presidencial, de número 4.726, aos 09 de julho de 2003, instituindo o Departamento de Ouvidoria Geral do Sistema Único de Saúde (DOGES), dando a este a responsabilidade de administrar e programar e concretizar a Politica Nacional de Ouvidorias do SUS, este que é um dos quatro pilares da Secretaria de Gestão Estratégica e Participativa (SGEP), criada pelo mesmo decreto. Assim, surgem as Ouvidorias no Brasil.

No caso, Brasil 2010a, expõe como ações da SGEP concretizar os princípios doutrinários e organizadores da Reforma Sanitária do SUS (universalidade, integralidade, equidade, participação comunitária, descentralização, hierarquização, regionalização e comando único em cada esfera do governo), incentivar os mecanismos populares de participação e controle social, além de auditar as contas do SUS, avaliando e monitorando os resultados das políticas publicas de saúde. E nesta dimensão da ação do SGEP está a avaliação da Estratégia Saúde da Família.

Por questão informativa, tal Decreto Presidencial chegou a ser revogado por dois outros, sendo o primeiro em 13 de julho de 2006, pelo Decreto $n^{\circ}$. 5.841, o qual cria o Sistema do OuvidorSUS, e pelo atual regime em vigor, de número 6.860, assinado aos 27 de maio de 2009, viabilizando o Sistema Nacional de Ouvidorias do SUS, que foi consumado em 2010 com a sua divulgação para todas as instancias federadas do Brasil (BRASIL, 2010b).

Com esta evolução da promoção de um serviço que favoreça uma participação social mais intensa, a determinação das Ouvidorias tornou-se atualmente como um Centro de Dados relevantes 
para se criar, avaliar e aperfeiçoar as políticas públicas. Na saúde, isto se faz em sua essência. Em si, podem ser registrados nos serviços de Ouvidoria: reclamações, solicitações, informações, elogios e sugestões, isto além de colher denúncias sobre a forma de como estão sendo oferecidos os serviços de saúde na comunidade. Estes dados são essenciais para que se possam criar estratégias de gerenciamento essenciais para a melhoria dos serviços realizados. É por meio deste principio que atualmente o SUS é constantemente avaliado na Federação Brasileira.

Por sua vez, ao se analisar a forma de desenvolvimento do Programa de Atenção Básica a Saúde sabe-se que este possui suas bases no Programa de Agentes Comunitários de Saúde (PACS) que foi oficializado em 1991, sendo que desde 1987, tal programa foi aplicado em sua primeira experiência no Estado do Ceará. Este em si, equivale ao germe da atual estratégia básica de saúde vigente no Brasil (BRASIL, 2005). Em si, o Programa Saúde da Família (PSF) surge como uma estratégia de reorientação do modelo assistencial da atenção básica, para fazer acontecer os princípios do Sistema Único de Saúde (ROSA; LABATE, 2005).

Entretanto, vale ressaltar que as estratégias de saúde promovidas pelo governo brasileiro, em bom percurso de sua história, nem sempre visava o bem-estar da população, mas era fruto do momento vivido pelo mesmo governo. Rosa e Labate (2005) afirmam que o PSF iniciou com a promulgação dos PACS os quais tinham por finalidade contribuir para a redução das mortalidades infantil e materna, que eram consideradas nas regiões Norte e Nordeste do Brasil. Com o sucesso dos serviços básicos de saúde, o PACS foi apresentado como uma proposta de promover a Saúde Familiar, vindo assim a ser pauta em uma reunião convocada pelo gabinete do Ministro da Saúde Henrique Santillo, impulsionado com o sistema de Saúde Familiar desenvolvido em Cuba. Esta aconteceu nos dias 27 e 28 de dezembro de 1993.

Em sua essência, o PACS funcionava com agentes comunitários de saúde coordenados por enfermeiros, os quais avaliavam e concretizavam os serviços básicos de saúde em uma determinada área geográfica. O fruto maior da reunião de dezembro de 1993 foi à idealização de uma expansão do PACS o qual correspondeu ao conhecido Programa Saúde da Família, inicialmente composto por um grupo de Agentes Comunitários de Saúde, coordenado por um enfermeiro, e junto com este atuavam um médico e um técnico de enfermagem. Com este quadro humano, pode-se constatar que uma Equipe de Saúde da Família bem estruturada e comprometida com o trabalho, tende a resolver $85 \%$ dos problemas de saúde em sua comunidade (ROSA; LOBATO, 2005).

Tendo em vista a dimensão política que a Estratégia Saúde da Família ganhou; Lourenção e Soler (2004), afirmaram que a razão da Saúde da Família apresentada no Programa idealizado em 1993 e concretizado em 1994, é reorganizar a prática assistencial em novas bases e critérios, substituindo o modelo tradicional da assistência médica vigente que pregava a cura e a prática hospitalar. No caso, a partir dos PSF's a atenção teria que centrar-se na família, onde o intuito fixava na prevenção das enfermidades e na promoção do bem-estar social, físico e mental em sua essência. 
Como então identificar a viabilidade dos serviços desenvolvidos na Estratégia da Saúde da Família? É nesta interrogação que a Ouvidoria entra como uma fonte de respostas e de promoção de informações importantes para a boa manutenção, desenvolvimento e aperfeiçoamento dos serviços desenvolvidos na Atenção Básica. É neste pressuposto que se concentra o presente trabalho.

\section{Método}

Este é um estudo de natureza quanti-qualitativa, exploratória e descritiva, realizado em uma determinada cidade do sul do estado do Ceará, no decorrer do ano de 2011, onde os dados coletados eram oriundos das manifestações dos cidadãos desta realizadas na Ouvidoria Municipal de Saúde, referentes aos serviços de saúde desenvolvidos, onde se procuraram levar em consideração somente aqueles relacionados a casos pertinentes aos serviços de Atenção Básica deste. Neste passo, sendo o mesmo, exclusivamente bibliográfico, os dados foram avaliados pela análise de conteúdo e expostos sob a forma de tabelas e quadros.

\section{Resultados}

Durante os meses de janeiro a dezembro de 2011, em uma determinada ouvidoria municipal de saúde do sul do estado do Ceará, foi possível constatar 187 manifestações relacionadas aos serviços de Atenção Básica de 803 registros notificados, o que equivale a 23,3\% do total de manifestações. Destas: 112 (59,9\%) eram reclamações; 28 (14,9\%) solicitações; 19 (10,2\%) informações; 16 (8,5\%) denúncias; 08 (4,3\%) elogios; e 04 (2,2\%) foram de sugestões. No geral, foram constatadas: 202 $(25,5 \%)$ de reclamações; $521(64,8 \%)$ de solicitações; 24 (2,9\%) de informações; 38 (4,7\%) de denúncias; $10(1,2 \%)$ de elogios; e $08(0,9 \%)$ de sugestões.

Tabela 1 - Relação entre as Manifestações Gerais com as Evidencias na Atenção Básica

\begin{tabular}{c|c|c|c|c}
\hline \multirow{2}{*}{ Tipo da Manifestação } & \multicolumn{2}{|c|}{ GERAL } & \multicolumn{2}{c}{ ATENÇ̃̃O BÁSICA } \\
\cline { 2 - 5 } & Bruto & Relativo & Bruto & Relativo \\
\hline Informações & 024 & $\mathbf{0 2 , 9 \%}$ & 019 & $\mathbf{1 0 , 2 \%}$ \\
\hline Sugestões & 008 & $\mathbf{0 0 , 9 \%}$ & 004 & $\mathbf{0 2 , 2 \%}$ \\
\hline Denuncias & 038 & $\mathbf{0 4 , 7 \%}$ & 016 & $\mathbf{0 8 , 5 \%}$ \\
\hline Solicitações & 521 & $\mathbf{6 4 , 8 \%}$ & 028 & $\mathbf{1 4 , 9 \%}$ \\
\hline Reclamações & 202 & $\mathbf{2 5 , 5 \%}$ & 112 & $\mathbf{5 9 , 9 \%}$ \\
\hline Elogios & 010 & $\mathbf{0 1 , 2 \%}$ & 008 & $\mathbf{0 4 , 3 \%}$ \\
\hline Total & 803 & $\mathbf{1 0 0 \%}$ & 187 & $\mathbf{1 0 0 \%}$ \\
\hline
\end{tabular}

Fonte: Direta, 2011. 
Tais números expressam a significância da Atenção Básica nos serviços à saúde desempenhados em uma cidade. Em si, considera-se a argumentação de que se esta dimensão da saúde se encontra bem estruturada, então todos os demais setores de saúde, por sua vez, estarão também organizados. Neste aspecto está a importância da constante avaliação do mesmo. Esta é possível por meio da Ouvidoria.

A abrangência da Atenção Básica é tão enfática que comparando com os demais setores onde foram registradas manifestações na Ouvidoria Municipal pelos usuários do SUS em tal cidade ao sul do Ceará, esta dimensão das políticas de saúde foi a que apresentou o segundo maior número de manifestações, vindo a perder somente do Setor de Regulação dos Exames, Cirurgias e Consultas Especializadas, conhecida por Central de Marcação, que sozinha acumulou 401 manifestações, sendo destas, $397(99,1 \%)$ solicitações de procedimentos atrasados, oriundos das unidades da ESF, 03 $(00,7 \%)$ reclamações e $01(00,2 \%)$ sugestão.

Por sua vez, associados à Atenção Básica estão os serviços de Saúde Bucal, onde nestes, foram constatados ao todo, 35 (4,5\%) manifestações, sendo ao todo, $17(48,6 \%)$ reclamações, 16 $(45,7 \%)$ solicitações e $02(05,7 \%)$ sugestões. Em sua essência, as manifestações na Saúde Bucal estão intercaladas com as atitudes dos odontólogos e dos seus respectivos auxiliares. Diante disto, podem ser somatizados aos números gerais da Ouvidoria 2011 sobre a Atenção Básica.

Tabela 2 - Perfil dos Profissionais da ABS segundo as Manifestações na Ouvidoria

\begin{tabular}{c|c|c|c|c|c|c|c|c|c|c}
\hline & \multicolumn{2}{|c|}{ Solicitação } & \multicolumn{2}{|c|}{ Informação } & \multicolumn{2}{c|}{ Elogio } & \multicolumn{2}{c|}{ Sugestão } & \multicolumn{2}{c}{ Denúncia } \\
\hline Médico & 013 & $46,4 \%$ & 007 & $36,8 \%$ & 004 & $50,0 \%$ & 002 & $50,0 \%$ & 004 & $25,0 \%$ \\
\hline Enfermeiro & 008 & $28,5 \%$ & 004 & $21,1 \%$ & 002 & $25,0 \%$ & 001 & $25,0 \%$ & 003 & $18,7 \%$ \\
\hline Odontólogo & 004 & $14,3 \%$ & 003 & $15,8 \%$ & 001 & $12,5 \%$ & - & - & - & - \\
\hline ACS & 003 & $10,8 \%$ & 005 & $26,3 \%$ & 001 & $12,5 \%$ & 001 & $25,0 \%$ & 005 & $31,3 \%$ \\
\hline Téc. Enf. & - & - & - & - & - & - & - & - & 002 & $12,5 \%$ \\
\hline Serv. Ger. & - & - & - & - & - & - & - & - & - & - \\
\hline Aux. Adm. & - & - & - & - & - & - & - & - & 002 & $12,5 \%$ \\
\hline TOTAL & \multicolumn{2}{|c|}{028} & \multicolumn{2}{|c|}{019} & \multicolumn{2}{|c|}{008} & \multicolumn{2}{c|}{004} & \multicolumn{2}{c}{016} \\
\hline
\end{tabular}

Fonte: Direta, 2011.

Entretanto, tendo em vista que com o presente documento espera-se identificar a relação entre gestão da Atenção Básica a Saúde e Ouvidoria, com o quadro abaixo foi possível apresentar fatores que revelam em quais pontos estruturais e funcionais devem ser revistos pela gestão para uma melhor promoção da atenção básica a comunidade. No caso, foi enfatizado neste as reclamações dos cidadãos desta, as atividades exercidas pelos profissionais da ABS da cidade estudada. Em si, dentre as reclamações, merecem destaque o número considerado tendo como referencia os profissionais médicos e agentes comunitários de saúde (ACS), estes que mais apresentam manifestações contra as 
suas atividades no setor de ouvidoria, totalizando um valor de $34,8 \%$ e $16,9 \%$ respectivamente. Os mesmos são seguidos pelos enfermeiros $(15,1 \%)$ e técnicos de enfermagem $(12,5 \%)$, sendo ainda notificadas reclamações enter os odontólogos $(5,3 \%)$, auxiliar de serviços gerais $(3,5 \%)$ e auxiliar administrativo $(11,6 \%)$.

Tabela 3 - Balanço das Reclamações associadas à ABS segundo na Ouvidoria

\begin{tabular}{c|c|c|c|c|c|c|c}
\hline & Médico & Enfermeiro & Odontólogo & ACS & T. Enf. & S. Ger. & Aux. Adm. \\
\hline Reclamação & 039 & 017 & 006 & 019 & 014 & 004 & 013 \\
\hline$\sum$ & \multicolumn{7}{|c}{112} \\
\hline
\end{tabular}

Fonte: Direta, 2011.

Assim, com este levantamento, foi possível traçar uma alínea entre as necessidades gerenciais que devem ser executadas na Atenção Básica, por meio dos relatos registrados na Ouvidoria desta cidade.

\section{Discussão}

Diante dos dados apresentados podem-se constatar alguns pontos importantes relacionados à relevância da construção de um programa de gestão a partir das manifestações apresentadas na Ouvidoria.

Dentre os primeiros pontos enfatiza-se a necessidade de garantir o direito do usuário do Sistema Único de Saúde, ao passo de proporcionar ao mesmo, condições eficazes e salutares para que este possa usufruir de forma legítima dos serviços oferecidos por tal sistema. Isto pode ser confirmado na consumação dos dados coletados e apresentados nos quadros outrora divulgados, onde foi possível identificar a relevância que os serviços da Atenção Básica possuem sobre uma gestão de saúde pública.

Em si, são os serviços oferecidos na Atenção Básica à essência para uma boa vivencia do SUS em um município. A importância desta dimensão da saúde pública é tão enfática que o setor líder de manifestações negativas na Ouvidoria do município estudado está intrinsecamente ligado aos serviços básicos de saúde. A Central de Marcação de Consultas tinha em suas mais de 400 notificações, como razão das manifestações, a marcação de consultas para um profissional de outra especialidade médica daquela solicitada pelo médico, vindo a ser justificado pelo digitador pela incompreensão gráfica do escrito no receituário, e outras relacionadas à demora da marcação do exame ou consulta solicitada devido ao não envio dos mesmos oriundos da Unidade de Saúde a Central de Marcação, em tempo imediato, ou ainda o fato de quando estes eram marcados e devolvidos a Unidade, os ACS não iam anunciar que a solicitação realizada havia sido solucionada e o resultado desta estava na unidade.

59 Id en line Revista de Psicologia. Ano 9, No. 27. Julho/2015 - ISSN 1981-1179. Edição eletrônica em http://idonline.emnuvens.com.br/id 
É essencial o bom funcionamento dos serviços básicos de saúde. Em si, se há uma boa eficiência destes na unidade básica, haverá como resultado uma diminuição no número de internações, na manifestação de epidemias e de outros agravos a saúde, isto porque há um conjunto de ações preventivas e imediatas aos elementos desfavoráveis a saúde do povo.

Diante do fato, para ter uma ideia de como estão sendo oferecidos os serviços de saúde, assim como identificar em que pontos precisam ser intensificados ou avaliados, a ouvidoria neste ponto, entra como um elemento fundamental para a construção de planos de ação eficazes na promoção de projetos e metodologias de programas de acordo com a opinião do povo. No caso, é fato de que manifestantes na Ouvidoria de qualquer município expõem somente as suas próprias opiniões, mas sim a de toda a comunidade em que está inserido, logo é o juízo fundamental que um gestor deve se fundamentar para realizar programas de saúde de acordo com o desejo do povo, sendo assim a construção de um serviço de saúde democratizada, isto porque não se fundamenta somente na visão de um ser, mas de uma comunidade, a qual expõe o que pensa, na ouvidoria.

São os ouvidores os responsáveis por ser a ponte entre a população, e o próprio servidor público, a gestão de um setor. No caso, do município estudado, os ouvidores se depararam, na Atenção Básica, com um número considerado de reclamações do que elogios e sugestões. Dentre solicitações de serviços, profissionais e condições de trabalho também foram notificadas. Entretanto, vale ressaltar que as denuncias que mantiveram um número considerado, onde ao comparar a quantidade de denuncias feitas no munícipio, 42,1\% se concentraram na Atenção Básica, o que revela uma insatisfação dos usuários com alguns profissionais que atuam nos serviços básicos de saúde. Quanto às reclamações, $55,4 \%$ destas estavam centradas aos serviços do setor estudado, confirmando tal insatisfação. Todavia, de forma até que paradoxal, dos elogios registrados, $80 \%$ estavam centrados aos serviços desempenhados na Atenção Básica, assim como de 50\% das sugestões notificadas.

Mas, destacando as reclamações, especificamente presta-se certa relevância aquelas feitas aos médicos quanto ao fato destes deixarem a unidade em um tempo inferior ao esperado e assinalado em concurso municipal, podendo assim constatar uma falta de compromisso com a comunidade em que exercem suas atividades e o fato de alguns não realizarem com humanização suas consultas, desconsiderando a necessidade psicológica e até clínica do cliente, dando valor apenas ao que o cliente aparentemente expõe vindo a, em certas ocasiões, evitar até tal manifestação do pensamento.

Por continuidade, dentre as reclamações relacionadas ao enfermeiro, enfatizam-se a de que os enfermeiros não prestam o serviço com humanização e desconsideram a opinião do cliente, assim como o fato de que alguns não permanecem na unidade no tempo esperado e assinalado em concurso. Quanto aos odontólogos, o foco maior das reclamações a ele relacionadas está no fato de disponibilizarem um número pequeno de consultas por dia, tendo uma média de oito consultas ao dia e vinte e quatro por semana. Já quanto aos Agentes Comunitários de Saúde (ACS), de forma expressiva está como reclamação o fato de que alguns destes não visitarem a casa das famílias por eles cobertas, e 
de alguns não repassarem as mesmas, informações eferentes aos eventos de promoção à saúde no posto de saúde. Relacionados aos técnicos de enfermagem (T. Enf.) estão o fato destes, tratarem de forma desrespeitosa o cliente, assim como as queixas evidenciadas entre os profissionais de Auxiliar Administrativo (Aux. Adm.) e Auxiliar de Serviços Gerais (S. Ger.).

Por fim, percebe-se que se não valorizar de forma devida os serviços básicos de saúde, o gestor terá que enfrentar três pontos distintos de problemas que podem classificar a sua gestão como negativa:

1) O cliente: o qual deve estar a par de todos os serviços oferecidos pela gestão, assim como deve também receber os mesmos com respeito as suas limitações e sua condição psicológica, física, social e espiritual.

2) O servidor: onde o oferecimento de condições dignas de trabalho para os profissionais que atuam na atenção básica, e em paralelo, o acordo da corresponsabilidade destes, onde evidenciando a desconsideração destes para com os serviços públicos desempenhados, devem ser os mesmos avaliados e analisados se a sua permanecia no setor se faz mesmo necessária, vindo a estar pronto para dispor alguém que possa suprir a vaga deixada, ou auxiliar o mesmo, se este se encontrar sobrecarregado, todavia, o princípio da satisfação do funcionário e do cliente, onde o gerente deve manter o bem-estar daquele que presta o serviço e daquele que dele usufrui, é essencial para a manutenção de uma gerencia equilibrada e sem tantos problemas evidenciados quanto a sua concretização e;

3) Os setores que atuam de forma paralela e dependente ao gerenciado: onde a busca de parcerias e de metodologias de qualificação dos serviços é fundamental para a promoção destes, com qualidade, isto porque não estará somente restrito a uma única unidade, mas a uma rede de unidades, em que aquele que faz uso do serviço, está intimamente ligado. Tais pontos são trabalhados na Ouvidoria, tendo em vista que, no caso da saúde, é neste setor onde o gestor pode perceber os pontos negativos e positivos de sua gestão, assim como pode traçar planos de ação eficientes para trabalhar problemas existentes ou originários em sua gestão.

A característica de uma boa gestão é determinada naquela em que dá espaço para aqueles que são gerenciados possam participar, no caso, é a gestão participativa, onde os membros são colocados como responsáveis pelo sucesso do sistema em que estão inseridos. Este ato comportamental deve ser vivenciado de forma intensa na saúde. Caso contrário, os dados estatísticos nos relatórios de ouvidoria, apenas irão mostrar mais reclamações, solicitações e denuncias, do que informações, elogios e sugestões. 


\section{Conclusão}

Diante do estudo realizado, pode-se concluir que a Ouvidoria armazena informações importantes que podem ser usadas para a construção de uma política pública de saúde mais democrática e eficiente. É na Ouvidoria onde se concentra a opinião dos usuários dos serviços oferecidos, logo, para o gestor que quer desenvolver um trabalho que seja reconhecido pelo público e considerado por este satisfatório, então ele deve ter como base de fonte de dados para a construção do seu plano de ação, as manifestações apresentadas pela Ouvidoria. É com estes que ele pode avaliar como está o desempenho dos serviços por ele direta, e indiretamente, gerenciados, assim como pode melhorar, intensificar e até mesmo cancelar alguns que não estão sendo bem vistos pelo povo a quem é destinado.

A Ouvidoria também expõe para o gestor uma analise de como está o comportamento dos servidores que atuam no setor por ele gerenciado. Logo, por meio dela, o gestor também pode analisar como estão os recursos humanos por ele utilizados para a concretização do seu plano de ação.

Trazendo todos os dados oferecidos para o serviço de Atenção Básica, são os dados armazenados na Ouvidoria que podem dispor de informações eficazes para um bom desempenho desta no município. Todavia, a questão é o como e o quanto o gestor considerará os fatos registrados nas manifestações apresentadas aos ouvidores. Em si, é sim a ouvidoria a ponte que une a população e o servidor a gestão, mas, além de ponte, a ouvidoria funciona como um campo onde são coletadas as informações necessárias para identificar a vitalidade do setor gerenciado e como qualifica-lo e torna-lo mais eficiente.

\section{Referências}

BRASIL. Ministério da Saúde. Fundação Oswaldo Cruz. Saúde da Família: avaliação da implementação em dez grandes centros urbanos: síntese dos principais resultados / Ministério da Saúde, Fundação Oswaldo Cruz; [elaborado por Sarah Escorel (Coord.); Lígia Giovanella; Maria Helena Mendonça; Rosana Magalhães; Mônica de Castro Maia Senna]. - 2. ed. atual. - Brasília: Editora do Ministério da Saúde, 2005. 210 p.: il. color. - (Série C. Projetos, Programas e Relatórios)

BRASIL. Ministério da Saúde. Secretaria-Executiva. Direitos dos usuários dos serviços e das ações de saúde no Brasil: legislação federal compilada - 1973 a 2006 / Ministério da Saúde, SecretariaExecutiva. - Brasília: Editora do Ministério da Saúde, 2007. 504 p. - (Série E. Legislação de Saúde).

BRASIL. Ministério da Saúde. Secretaria de Gestão Estratégica e Participativa. Departamento de Ouvidoria-Geral do SUS. Ouvidoria-Geral do SUS: um espaço de cidadania / Ministério da Saúde, Secretaria de Gestão Estratégica e Participativa, Departamento de Ouvidoria-Geral do SUS. - Brasília: Editora do Ministério da Saúde, 2010. 20 p.: il. - (Serie F. Comunicação e Educação em Saúde) 
BRASIL. Ministério da Saúde. Secretaria de Gestão Estratégica e Participativa. Departamento de Ouvidoria-Geral do SUS. Falando de Ouvidoria: experiências e reflexões: Ministério da Saúde, Secretaria de Gestão Estratégica e Participativa, Departamento de Ouvidoria-Geral do SUS - Brasília: Editora do Ministério da Saúde, 2010. 93 p.: il. - (Série B. Textos Básicos de Saúde)

ROSA, W.A.G.; LABATE, R.C., Programa Saúde da Família: A Construção de um Novo Modelo de Assistência. Rev. Latino-americana de Enfermagem, 2005. Novembro-Dezembro 13 (6): 1027-34.

Como citar este artigo (Formato ABNT):

ALMEIDA, S.L.; MATOS, S.K.C.; PAZ, C.B.; SANTANA, O.M.L.L.; CARVALHO, C.M.L.; OLIVEIRA, G.F. Atenção Básica e Ouvidoria: Um perfil da Interação População e Gestão. Id on Line Revista de Psicologia, Julho de 2015, vol.9, n.27, p. 52-63. ISSN 1981-1189.

Recebido: 06/05/2015

Aceito: $10 / 05 / 2015$ 